\title{
New Strategies in Neurogenic Heterotopic Ossification
}

Margarita-Michaela Ampadiotaki ${ }^{1}$, Dimitrios S. Evangelopoulos ${ }^{2}$, Dimitrios Pallis ${ }^{1}$, Christos Vlachos ${ }^{2}$, John Vlamis ${ }^{2}$, Maria-Eleftheria Evangelopoulos ${ }^{3}$

1. 2nd Orthopaedic Department, KAT Hospital, Athens, GRC 2. 3rd Orthopaedic Department, KAT Hospital, National and Kapodistrian University of Athens School of Medicine, Athens, GRC 3. 3rd Department of Neurology, National and Kapodistrian University of Athens, Aiginition Hospital, Athens, GRC

Corresponding author: Margarita-Michaela Ampadiotaki, marab.ortho@gmail.com

\begin{abstract}
The term neurogenic heterotopic ossification (NHO) is used to describe the pathological bone formation in soft tissues, due to spinal cord or brain injury. Commonly is presented with pain and stiffness of the affected joint. NHO affects the quality of life of these patients, delays their rehabilitation and therefore increases morbidity. The aim of this article is to emphasize pathophysiology mechanism and review new molecular treatments of heterotopic ossification (HO). It was demonstrated that potent treatment strategies are based on understanding the molecular mechanisms and aiming to inhibit the pathological process of the $\mathrm{HO}$ in various stages. New treatments are targeting several factors such as bone morphogenetic proteins (BMPs), retinoic acid receptors (RARs), hypoxic inhibitors (Hif1-inhibitors, rapamycin), free radical scavengers and immunological agents (imatinib). The endogenous pathways that lead to $\mathrm{HO}$ at molecular and cellular levels have been the aim of many studies in recent years. New treatment options for HO should be recommended due to the ineffectiveness of traditional older options, such as anti-inflammatory drugs and radiation, especially in the case of NHO.
\end{abstract}

Categories: Orthopedics, Trauma

Keywords: neurogenic heterotopic ossification, spinal cord injury, molecular treatment

\section{Introduction And Background}

Heterotopic ossification (HO) is defined as the extraskeletal bone formation in soft tissues, blood vessels, ligaments and muscles [1]. HO described for the first time during World War I as a complication of blast injuries and constitutes a serious reason of morbidity in soldiers. It is associated with many factors, such as trauma, burns, rare congenital diseases, brain and spinal cord injuries (SCI) [1]. Inflammatory pathways have been suggested so far to play an important role in HO. Three types of HO have been described; traumatic, neurogenic and hereditary [2].

Review began 04/14/2021 Review ended 04/24/2021 Published 04/27/2021

\section{Copyright 2021}

Ampadiotaki et al. This is an open access article distributed under the terms of the Creative Commons Attribution License CC-BY 4.0., which permits unrestricted use, distribution, and reproduction in any medium, provided the original author and source are credited.
In this study, a thorough review on neurogenic heterotopic ossification (NHO), following SCI was performed. Although etiology still remains obscure, nowadays a correlation between triggering factors, progenitor cells' differentiation into cartilage and bone is attempted [3,4].

In the recent years, treatment of $\mathrm{HO}$ is based on surgical resection following NHO maturation. However, it is pivotal to find out prophylactic treatment in order to prevent SCI-patients from HO

[5]. Although nonsteroidal anti-inflammatory drugs (NSAIDs) and irradiation remain the basic prophylactic methods against HO, new molecular therapies are investigated. Furthermore, the fact that common pathophysiological mechanisms may lead to different types of HO triggers research for new molecular therapies [2].

This review provides an overview of NHO pathophysiology, conceivable treatments and possible therapeutic targets.

\section{Review}

\section{Epidemiology}

NHO prevalence in SCI patients has been estimated to be between $10 \%$ and 53\% [6]. In the study of Rawat et al., 6.3\% of SCI patients developed HO, mostly at the hip joint [6]. The prevalence of NHO after SCI is lower in pediatric patients than in adults. Moreover, it has been described as spontaneous desorption of the lesions among children [7].

\section{Risk factors}

Many factors have been associated with the onset of NHO, including the duration of coma, the need for artificial ventilation and tracheostomy, and the development of vascular stasis, pneumonia or other 


\section{Cureus}

infections. Additionally, the level of SCI is of crucial importance. Low cervical or high thoracic lesions increase the risk for NHO [8]. The disease always appears caudally to the lesion level, mainly in hip knee, elbow and shoulder joints. Other risk factors include male sex, young age and the development of autonomic dysreflexia $[8,9]$.

\section{Clinical presentation}

NHO develops within two to four months following SCI with persistent pain, swelling, erythema, warmth and decreased range of motion. In the early stage, it is presented with localized pain, swelling and tenderness. During this phase, lesions consist of collagen fibers and fibroblasts, demonstrate high turnover and may be confused with osteosarcoma. In later stages, mature bone tissue is developed and swelling is limited. Joint range of motion is decreased affecting normal posture, leading to joint stiffness, limitation of daily activities, ankylosis and ulcerations of the skin [10].

\section{Classification systems}

Many classification systems have been proposed for HO [11]. Mavrogenis et al. suggested a classification system for NHO of the hip [12]. However, Brooker's classification, based solely on plain radiograms, remains the most commonly used [11].

\section{Laboratory tests and radiological images}

In the early stages, alkaline phosphatase (ALP) increases with a pick at 10 weeks. Levels of calcium, phosphorous, C-reactive protein (CRP), erythrocyte sedimentation rate (ESR), Creatine phosphokinase (CPK), matrix metalloproteinase 9 (MMP9) and IL-3 have been suggested as follow-up markers; however, their use remains controversial [13].

Plain X-ray is the initial imaging study for HO diagnostic algorithm (Figure 1).

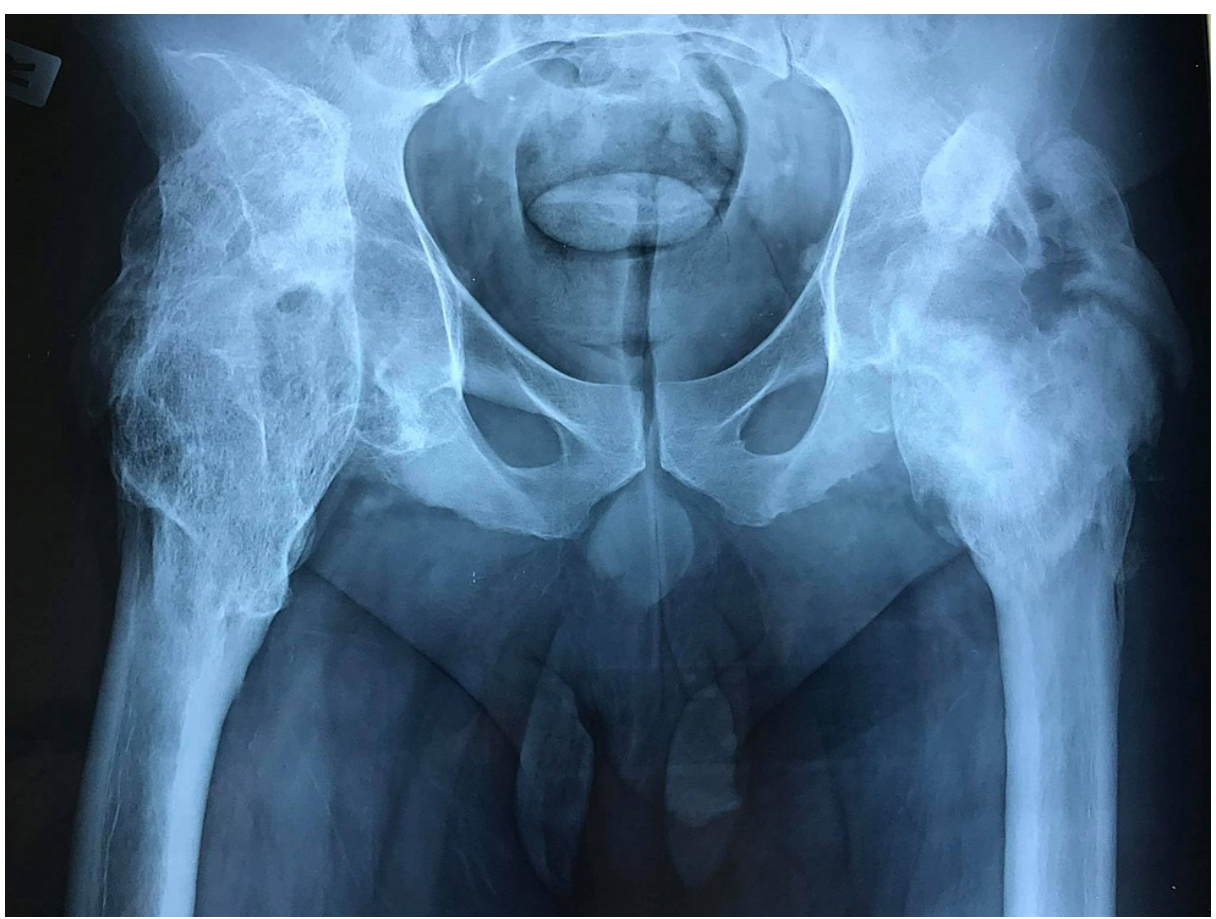

FIGURE 1: Anteroposterior X-ray of a 38-year-old paraplegic patient showing neurogenic heterotopic ossification in both hips following T1 fracture.

Nuclear bone scans and ultrasonography represent useful early diagnostic tools, specifically for patients following SCI while computed tomography (CT) and magnetic resonance imaging (MRI) are applied mainly for the diagnosis of mature $\mathrm{HO}[14,15]$. The three-phase radionuclide bone scan still remains the "gold standard" for early HO detection [16].

\section{Pathogenesis of $\mathrm{HO}$}

Neuroinflammation 
SCI initiates a cascade of pathophysiological changes that lead to heterotopic bone formation. Especially, neuroinflammatory substances such as oncostatin M (OSM), glutamate, substance P, calcitonin gene-related protein (CGRP), transforming growth factor beta (TGF- $\beta$ ) and leptin are produced from the injured spinal cord and activate immune cells such as macrophages [17]. In addition, lesions of the spinal cord damage blood barrier integrity and permit transfer of additional inflammatory molecules [18].

In the early stage, local inflammation, as a response to spinal cord and peripheral tissues' injury (muscle, fracture, etc.), initiates a cellular and molecular cascade [5]. During this stage, inflammatory cells, such as macrophages, lymphocytes and mast cells are gathered in the perivascular area of $\mathrm{HO}$ lesions, triggering progenitor cells' proliferation [19].

Bone tissue develops from progenitor cells, through endochondral and intramembranous pathways. HO commonly occurs by endochondral ossification [20]. Tissue-derived mesenchymal stem cells (MSCs) participate in bone healing and heterotopic bone formation by differentiating into osteoblasts, chondrocytes or adipocytes. Local microenvironment has been shown to affect these pathways [21]. Injury-induced hypoxia activates HIF1a, a protein which triggers the differentiation of progenitor cells into osteoblasts and chondrocells. Current studies suggest that mesenchymal progenitor cells (MPCs) of traumatically injured muscle actively participate in HO formation [19]. Furthermore, cells such as pericytes, vascular endothelial cells, skeletal muscle cells, hematopoietic cells, mast cells and MPCs have osteogenic abilities and participate in $\mathrm{HO}$ formation [4].

Although local inflammation leads to the expansion and differentiation of multiple cells, the exact pathway for $\mathrm{HO}$ remains yet unclear. The differentiation of progenitor cells towards a chondrogenic lineage and endochondral ossification depends on factors, such as BMP signaling, SOX and hypoxic conditions [20]. On the other hand, differentiation towards osteogenesis and bone formation is supported through vascularization, Wnt/ $\beta$-catenin signaling and nuclear factors (Runx2 and Osterix) [21]. Kan et al reported a common mechanism for all types of $\mathrm{HO}$ [4]. Furthermore, current studies present the important role of BMP, Hedgehog (HH), Wnt/ $\beta$-catenin, FGF, and HIF-1 $\alpha$ [22] .

Bone Morphogenetic Protein (BMP) signaling

BMPs belong to the family of transforming growth factor $\beta$ (TGF $\beta$ ). BMPs-induced bone formation occurs under pathological procedures. Expression of BMP-2, 4, 7 and 9 was upregulated in animal models with SCIinduced HO. BMP-9 is also implicated in HO pathophysiology and depends on muscles' microenvironment [23]. Studies on fibrodysplasia ossificans progressiva (FOP) and traumatic brain injury (TBI) patients report potent BMP signaling [18].

Hedgehog Signaling

The Hedgehog $(\mathrm{HH})$ signaling pathway induces chondrocyte and osteoblast lineage differentiation. $\mathrm{HH}$ is implicated in osteogenesis during fracture-healing through regulation of angiogenesis [24]. Absence of GNAS leads to HH signaling increase, in mesenchymal progenitor cells. Moreover, the literature supports that $\mathrm{HH}$ inhibitors may prevent progressive osseous heteroplasia ( $\mathrm{POH})$ and other forms of $\mathrm{HO}$ [24].

HIF1a (Hypoxia-Inducible Factor-1 $\alpha$ )

NHO is caused by hypoxia-induced tissue damage [25]. Tissue ischemia, due to vascular system damage, leads to immune cell response and cell proliferation. Hypoxic environments induce chondrogenic cell differentiation. HIF-1 $\alpha$ is a regulator of cellular hypoxic responses [25]. HIF-1a is significantly up-regulated during chondrogenic differentiation, in contrast to decreasing levels in the osteogenic stage [26]. Oxygen deficiency inhibits cell growth and increases apoptosis. Furthermore, the stability of HIF- $1 \alpha$ increases genetranscription, enhancing adaptation to hypoxia. Studies have shown that hypoxia, through HIF1a, affects the production of BMP, VEGF and cytokines, increases chondrogenic cells proliferation and promotes ectopic bone formation [27]. Wang et al. presented the correlation between inflammation and hypoxia [26]. The authors stated that cellular hypoxia enhances heterotopic endochondral ossification by exaggerating BMP-signaling through rabaptin 5 (RABEP1)-mediated retention of activin A receptor type I (ACVR1). Activin A probably plays an important role in NHO, since high levels of this substance have been detected in the serum of these patients [27]. Agarwal et al. stated that HIF-1 $\alpha$ is crucial for all forms of HO [28].

\section{Mammalian Target of Rapamycin ( $m$ TOR)}

The mTOR signaling not only enhances the angiogenetic role of HIF1a but also activates vascular endothelial growth factor VEGF. In addition, mTOR signaling pathway is implicated in chondrogenic differentiation. Studies on FOP patients showed that mutation of ACVR1 receptor and abnormal Activin levels lead to increased mTOR signaling [29].

Retinoic Acid Receptor (RAR) Signaling 
There are three types of RARs; RAR $\alpha$, RAR $\beta$, RAR $\gamma$, which are inhibitors of chondrogenesis and cartilage formation. It has been found that only selective agonists of RARY are effective in preventing HO [30]. Recent literature data support their ability to block the consolidation of skeletal progenitor cells and their differentiation into chondrocytes [30].

\section{Treatment options}

Conventional Treatments

(i) NSAIDs (nonsteroidal anti-inflammatory drugs): Patients with NHO are presented with severe systemic inflammation. NSAIDs have been widely used for HO prevention and treatment. Ketorolac, ibuprofen, celecoxib and indomethacin are commonly used to prevent HO in patients after total hip arthroplasty. In trauma patients, their efficacy has not yet been proved [31]. Polytrauma patients suffer from additional injuries that may be negatively affected by the NSAIDs. Administration of NSAIDs following acute trauma may induce bleeding, gastritis and impair fracture healing. Nevertheless, a recent study on SCI patients showed that the use of NSAIDs during early injury stages may prevent HO development [31].

(ii) Radiation therapy: Radiotherapy affects mesenchymal cells, responsible for HO formation [32]. Singledose radiation therapy demonstrates good results on SCI-induced HO treatment. However, long-term side effects still remain unknown [32]. Cipriano et al, in a case-control study on NHO patients treated with radiation therapy, pointed out that the incidence of $\mathrm{HO}$ was higher in the treatment group (15.0\%) compared to the control group (5.1\%) [33].

\section{Novel Therapies}

(i) Biphosphonates: Biphosphonates promote osteoclasts' death and reduce calcification. Etidronate inhibits bone mineralization; however, organic matrix remains unaffected and bone formation reoccurs, if treatment continues for 6 months, following injury [34]. Furthermore, SCI patients, with no-visible lesions on CT-scan treated with etidronate, had a significantly lower incidence of $\mathrm{NHO}$, compared to patients with radiographically detectable NHO. If bone mineralization has already occurred, bisphosphonates are ineffective [34].

(ii) Inhibitors of BMPs: BMP-signaling is crucial for skeletal growth and HO formation [10]. The inhibitors of BMP; Noggin-glycoprotein- and BMP type 1 receptor inhibitors inhibit dimerization of BMP receptor and Smad-dependent signaling [10]. These inhibitors are effective in all stages of HO. However, side effects though BMP receptor inactivation have been described in multiple organs.

Noggin belongs to TGF- $\beta$ proteins and is implicated on skeletal growth [35]. Hannallah et al. studied Noggin in muscle-derived stem cells, in a range of doses. They suggested that the development of heterotopic ossification is inhibited by the block of BMPs [35]. Glaser et al stated that the local concentration of wildtype Noggin or the somatic cell gene transfer of a Noggin mutation can inhibit HO [36]. Overexpression of Noggin prompts osteopenia reduces bone mineralization and density. Additionally, it affects other organs, such as the pituitary, heart, prostate, thymus and parathyroid. Animals treated with Noggin showed no HO signs on X-rays, thus proving that gene therapy with Noggin is a promising method for HO treatment [37].

Transforming growth factor beta (TGF- $\beta$ ) has also been suggested as therapeutic option for HO. For HO inhibition, it may be advantageous to decrease the amount of phosphorus, essential for ATP and ADP increase. The differentiation of MSCs into osteochondral cells occurs through SMAD phosphorylation. In animal models, apyrase, a SMAD1/5/8 inhibitor, decreased the amount of HO [37]. Yu et al suggested that small molecule inhibition of BMP type I receptor could be beneficial in the treatment of FOP and heterotopic ossification associated with excessive BMP signaling [38]. In recent studies, minor molecule inhibition of TGF- $\beta$ activates kinase- 1 and reduces side effects, such as weight loss, delayed wound healing and infection [39].

(iii) Retinoic acid agonists-RARY: Of the three known types of retinoic acid receptors (RAR); $\alpha, \beta, \gamma$ known to prevent chondrogenesis, only retinoic acid receptor gamma (RARy) agonists are used for HO [13]. Retinoid acid prevents the differentiation of chondrogenic precursor cells into chondrocytes, in the early stages of HO. Palovarotene, a RAR-y agonist, already known from the clinical trial of $\alpha$-1-antitrypsin-induced emphysema is known to prevent the development of HO [40-43]. Moreover, the use of Palovarotene on patients with hereditary multiple exostoses resulted in a 50\% decrease of $\mathrm{HO}$ [19]. However, Palovarotene is teratogenic and prompts limb malformations in immature skeletons. Additionally, it may lead to pancreatitis, vision impairment, mucocutaneous ulcers and sensitivity to sunlight [44]. More studies are required to evaluate RARY efficacy, due to its wide expression, on chondrocytes and chondrogenic cells, compared to RARa and RARß [13].

(iv) Rapamycin- Inhibitor of hypoxia-inducible factor 1a-( HIF1a): It is well-known that hypoxia-inducible factor-1 $\alpha($ Hif $1 \alpha)$ orchestrates cellular adaptation to hypoxia. Hif1a is expressed in trauma-induced mouse models. BMP pathway is also enhanced by hypoxia. Literature data supports that the use of rapamycin, an 
Hif1a inhibitor, prevented HO formation in animal models [45]. Rapamycin is a macrolide immunosuppressant, which inhibits the mechanistic target of rapamycin (mTOR) protein kinase $[45,46]$. It blocks the mTOR pathway, preventing HIF-1 $\alpha$ translation without affecting its transcription. Rapamycin also inhibits the hypoxia-induced expression of VEGF [44, 45]. Despite its wide application on patients following kidney and liver transplant, its side effects are well-known, including hyperlipidemia, hypercholesterolemia, hypertriglyceridemia, glucose intolerance, insulin resistance and diabetes, anemia, thrombocytopenia, dermatological and gastrointestinal disorders, sinusitis, respiratory and urinary infections, and testicular dysfunction [45]. Maekawa et al. studied the use of rapamycin on ACVR1 mutant mice and pointed out that this macrolide decreased the occurrence of $\mathrm{HO}$ and reduced the amount of recurrent HO following surgical resection [46]. Recent data shows that, in knock-out HIF-1 $\alpha$ mice, HO progenitor cells are diminished [47].

(v) Free radical scavengers: The ischemia-reperfusion syndrome and the disuse phenomenon are the main causes of production of free radicals. Hypoxia-induced free radicals prompt oxidative damage to the cells and induce HO formation. Free radical scavengers such as allopurinol and N- acetylcysteine have been suggested as inhibitors of HO. An experiment in rodents pointed out that FR scavengers are effective in preventing HO. Their effectiveness was assessed as more potent than that of indomethacin [48].

(vi) Immune therapy-Imatinib: Imatinib is indicated generally for chronic myeloid leukemia. It is considered to be a safe medication with only mild side effects, such as: cramps, diarrhea, edema and skin rashes [49]. Platelet-derived growth factor (PDGF), responsible for neoangiogenesis at the final stages of endochondral ossification, is believed to participate in the HO formation [50]. It has been shown that imatinib is a potent PDGF inhibitor in murine models. The amount of $\mathrm{HO}$ was decreased up to $85 \%$, following the administration of imatinib. Other animal studies also demonstrated that imatinib blocks HIF1a and affects HO progression [24]. Furthermore, imatinib inhibits macrophages and mast cell proliferation as well as the excretion of metalloproteases. Nevertheless, it remains unknown how imatinib affects wound healing [50]. Kaplan et al., in the only study on human subjects, reported a small case series on seven children with FOP and pointed out the hopeful use of imatinib in HO prevention [49]. It is imperative to perform additional clinical trials to understand the profits of imatinib in the treatment of $\mathrm{HO}$ (Table 1). 


\section{Cureus}

\begin{tabular}{|c|c|c|c|}
\hline Author & Treatment & Model & Results \\
\hline $\begin{array}{l}\text { Chakkalakal } \\
\text { et al. [40] }\end{array}$ & Palovarotene & Mouse FOP trauma induced & $80 \%$ reduction of $\mathrm{HO}$ \\
\hline Genet et al. [3] & $\begin{array}{l}\text { Prophylactic depletion of macrophages } \\
\text { by clodronate-loaded liposomes }\end{array}$ & $\begin{array}{l}\text { Transection T7-T8 and } \\
\text { cardiotoxin injection in mice }\end{array}$ & $90 \%$ reduction of $\mathrm{NHO}$ \\
\hline $\begin{array}{l}\text { Pavey et al. } \\
\text { [13] }\end{array}$ & Palovarotene & 110 rats blast injured & $46 \%-100 \%$ reduction of $\mathrm{HO}$ \\
\hline $\begin{array}{l}\text { Shimono et al. } \\
\text { [41] }\end{array}$ & RAR agonist & Mouse BMP injected & $\begin{array}{l}\text { Reduction of the ratio mineralized tissue } \\
\text { volume/total volume histologically }\end{array}$ \\
\hline $\begin{array}{l}\text { Wheatley et } \\
\text { al. [42] }\end{array}$ & Palovarotene & $\begin{array}{l}\text { Blast-related amputation-72 } \\
\text { rodents }\end{array}$ & Reduction of cytokines \\
\hline $\begin{array}{l}\text { Agarwal et al. } \\
\text { [28] }\end{array}$ & Rapamycin & $\begin{array}{l}\text { Mice, burned and } \\
\text { genetically modified }\end{array}$ & Reduction of de novo $\mathrm{HO}$ formation \\
\hline $\begin{array}{l}\text { Hannallah et } \\
\text { al. [35] }\end{array}$ & Noggin & $\begin{array}{l}\text { Achilles tenontotomy in } \\
\text { mice }\end{array}$ & $83 \%$ reduction of $\mathrm{HO}$ \\
\hline $\begin{array}{l}\text { Lees-Shepard } \\
\text { et al. [19] }\end{array}$ & Palovarotene & Mouse genetic model & $50 \%$ reduction of $\mathrm{HO}$ \\
\hline $\begin{array}{l}\text { Maekawa et } \\
\text { al. [46] }\end{array}$ & Rapamycin & $\begin{array}{l}\text { Mice with mutation of } \\
\text { ACVR/ALK2 gene }\end{array}$ & $75 \%$ reduction of $\mathrm{HO}$ formation \\
\hline $\begin{array}{l}\text { Qureshi et al. } \\
\text { [45] }\end{array}$ & Rapamycin & Mice trauma induced & $90.3 \%$ reduction \\
\hline $\begin{array}{l}\text { Glaser et al. } \\
{[36]}\end{array}$ & Noggin & $\begin{array}{l}\text { BMP4-induced mouse } \\
\text { model }\end{array}$ & Noggin inhibited $\mathrm{HO}$ \\
\hline $\begin{array}{l}\text { Vanden } \\
\text { Bossche et al. } \\
\text { [48] }\end{array}$ & $\begin{array}{l}\text { Free radical scavengers [allopurinol and } \\
\mathrm{N} \text {-acetylcysteine] }\end{array}$ & Rabbits & Higher inhibitory effect than indomethacin \\
\hline $\begin{array}{l}\text { Zimmermann } \\
\text { et al. [47] }\end{array}$ & Echinomycin (HIF1a inhibitor) & $\begin{array}{l}\text { Murine model-Achilles } \\
\text { tenotomy }\end{array}$ & $90 \%$ reduction \\
\hline Yu et al. [38] & $\begin{array}{l}\text { Selective inhibitor of BMP type I } \\
\text { receptor kinases, LDN-193189 }\end{array}$ & Mouse FOP model & Reduction of $\mathrm{HO}$ \\
\hline $\begin{array}{l}\text { Peterson et al. } \\
\text { [37] }\end{array}$ & Apyrase & $\begin{array}{l}\text { Burn-Achilles tenotomy } \\
\text { mice }\end{array}$ & Decrease $\mathrm{HO}$ formation \\
\hline $\begin{array}{l}\text { Werner et al. } \\
\text { [50] }\end{array}$ & Imatinib & $\begin{array}{l}\text { Murine model Achilles } \\
\text { tenotomy }\end{array}$ & $85 \%$ reduction of $\mathrm{HO}$ \\
\hline
\end{tabular}

\section{TABLE 1: Molecular treatments and their efficacy.}

FOP: fibrodysplasia ossificans progressiva; HO: heterotopic ossification; NHO: neurogenic heterotopic ossification; RAR: retinoic acid receptors; BMP: bone morphogenetic proteins; HIF1a: hypoxia-inducible factor-1a.

\section{Conclusions}

This article is a review of the current literature on neurogenic heterotopic ossification. Limitation of this review is the small samples of studies on NHO. Traditional management of heterotopic ossification included NSAIDs, radiation therapy and surgical excision. However, since traditional therapies are not always effective, recent studies focus on pathophysiologic pathways to develop new molecular therapies. As neurogenic heterotopic ossification remains a major cause of disability and morbidity for SCI patients, it is imperative to perform more studies to clarify the safety and the effectiveness of these therapies.

\section{Additional Information}

\section{Disclosures}


Conflicts of interest: In compliance with the ICMJE uniform disclosure form, all authors declare the following: Payment/services info: All authors have declared that no financial support was received from any organization for the submitted work. Financial relationships: All authors have declared that they have no financial relationships at present or within the previous three years with any organizations that might have an interest in the submitted work. Other relationships: All authors have declared that there are no other relationships or activities that could appear to have influenced the submitted work.

\section{References}

1. Meyers C, Lisiecki J, Miller S, et al.: Heterotopic ossification: a comprehensive review. JBMR Plus. 2019, 3:e10172. 10.1002/jbm4.10172

2. Xu R, Hu J, Zhou X, Yang Y: Heterotopic ossification: mechanistic insights and clinical challenges. Bone. 2018, 109:134-42. 10.1016/j.bone.2017.08.025

3. Genêt F, Kulina I, Vaquette C, et al.: Neurological heterotopic ossification following spinal cord injury is triggered by macrophage-mediated inflammation in muscle. J Pathol. 2015, 236:229-40. 10.1002/path.4519

4. Kan C, Chen L, Hu Y, et al.: Conserved signaling pathways underlying heterotopic ossification . Bone. 2018, 109:43-8. 10.1016/j.bone.2017.04.014

5. Genêt F, Denormandie P, Keenan MA: Orthopaedic surgery for patients with central nervous system lesions: Concepts and techniques. Ann Phys Rehabil Med. 2019, 62:225-33. 10.1016/j.rehab.2018.09.004

6. Rawat N, Chugh S, Zachariah K, Ghosh S: Incidence and characteristics of heterotopic ossification after spinal cord injury: a single institution study in India. Spinal Cord Ser Cases. 2019, 5:72. 10.1038/s41394-0190216-6

7. Hitzig SL, Tonack M, Campbell KA, McGillivray CF, Boschen KA, Richards K, Craven BC: Secondary health complications in an aging Canadian spinal cord injury sample. Am J Phys Med Rehabil. 2008, 87:545-55. 10.1097/PHM.0b013e31817c16d6

8. Sullivan MP, Torres SJ, Mehta S, Ahn J: Heterotopic ossification after central nervous system trauma: a current review. Bone Joint Res. 2013, 2:51-7. 10.1302/2046-3758.23.2000152

9. Putz C, Helbig L, Gerner HJ, Zimmermann-Stenzel M, Akbar M: Autonomic dysreflexia: a possible trigger for the development of heterotopic ossifications after traumatic spinal cord injury?: a clinical longitudinal study. Eur J Trauma Emerg Surg. 2014, 40:721-6. 10.1007/s00068-013-0353-8

10. Cipriano CA, Pill SG, Keenan MA: Heterotopic ossification following traumatic brain injury and spinal cord injury. J Am Acad Orthop Surg. 2009, 17:689-97. 10.5435/00124635-200911000-00003

11. Hug KT, Alton TB, Gee AO: Classifications in brief: Brooker classification of heterotopic ossification after total hip arthroplasty. Clin Orthop Relat Res. 2015, 473:2154-7. 10.1007/s11999-014-4076-X

12. Mavrogenis AF, Guerra G, Staals EL, Bianchi G, Ruggieri P: A classification method for neurogenic heterotopic ossification of the hip. J Orthop Traumatol. 2012, 13:69-78. 10.1007/s10195-012-0193-Z

13. Pavey GJ, Qureshi AT, Tomasino AM, et al.: Targeted stimulation of retinoic acid receptor- $\gamma$ mitigates the formation of heterotopic ossification in an established blast-related traumatic injury model. Bone. 2016, 90:159-67. 10.1016/j.bone.2016.06.014

14. Rosteius T, Suero EM, Grasmücke D, et al.: The sensitivity of ultrasound screening examination in detecting heterotopic ossification following spinal cord injury. Spinal Cord. 2017, 55:71-3. 10.1038/sc.2016.93

15. Argyropoulou MI, Kostandi E, Kosta P, et al.: Heterotopic ossification of the knee joint in intensive care unit patients: early diagnosis with magnetic resonance imaging. Crit Care. 2006, 10:R152. 10.1186/cc5083

16. Harris M, Cilwa K, Elster EA, Potter BK, Forsberg JA, Crane NJ: Pilot study for detection of early changes in tissue associated with heterotopic ossification: moving toward clinical use of Raman spectroscopy. Connect Tissue Res. 2015, 56:144-52. 10.3109/03008207.2015.1013190

17. Alizadeh A, Dyck SM, Karimi-Abdolrezaee S: Traumatic spinal cord injury: an overview of pathophysiology, models and acute injury mechanisms. Front Neurol. 2019, 10:282. 10.3389/fneur.2019.00282

18. Brady RD, Grills BL, Romano T, Wark JD, O'Brien TJ, Shultz SR, McDonald SJ: Sodium selenate treatment mitigates reduction of bone volume following traumatic brain injury in rats. J Musculoskelet Neuronal Interact. 2016, 16:369-76.

19. Lees-Shepard JB, Goldhamer DJ: Stem cells and heterotopic ossification: Lessons from animal models . Bone. 2018, 109:178-86. 10.1016/j.bone.2018.01.029

20. Convente MR, Chakkalakal SA, Yang E, et al.: Depletion of mast cells and macrophages impairs heterotopic ossification in an Acvr1R206H mouse model of fibrodysplasia ossificans progressiva. J Bone Miner Res. 2018, 33:269-82. 10.1002/jbmr.3304

21. Pacifici M: Acquired and congenital forms of heterotopic ossification: new pathogenic insights and therapeutic opportunities. Curr Opin Pharmacol. 2018, 40:51-8. 10.1016/j.coph.2018.03.007

22. Agarwal S, Drake J, Qureshi AT, et al.: Characterization of cells isolated from genetic and trauma-induced heterotopic ossification. PLoS One. 2016, 11:e156253. 10.1371/journal.pone.0156253

23. Wang YK, Sun WF, Liu XG, Deng J, Yan BE, Jiang WY, Lin XB: Comparative study of serum levels of BMP-2 and heterotopic ossification in traumatic brain injury and fractures patients. Zhongguo Gu Shang. 2011, 24:399-403.

24. Reichel LM, Salisbury E, Moustoukas MJ, Davis AR, Olmsted-Davis E: Molecular mechanisms of heterotopic ossification. J Hand Surg Am. 2014, 39:563-6. 10.1016/i.jhsa.2013.09.029

25. Taheem DK, Foyt DA, Loaiza S, et al.: Differential regulation of human bone marrow mesenchymal stromal cell chondrogenesis by hypoxia inducible factor- $1 \alpha$ hydroxylase inhibitors. Stem Cells. 2018, 36:1380-92. 10.1002/stem.2844

26. Wang H, Lindborg C, Lounev V, et al.: Cellular hypoxia promotes heterotopic ossification by amplifying BMP signaling. J Bone Miner Res. 2016, 31:1652-65. 10.1002/jbmr.2848

27. Huang Y, Wang X, Lin H: The hypoxic microenvironment: a driving force for heterotopic ossification progression. Cell Commun Signal. 2020, 18:20. 10.1186/s12964-020-0509-1

28. Agarwal S, Loder S, Brownley C, et al.: Inhibition of Hif1 $\alpha$ prevents both trauma-induced and genetic heterotopic ossification. Proc Natl Acad Sci U S A. 2016, 113:E338-47. 10.1073/pnas.1515397113 
29. Hino K, Horigome K, Nishio M, et al.: Activin-A enhances mTOR signaling to promote aberrant chondrogenesis in fibrodysplasia ossificans progressiva. J Clin Invest. 2017, 127:3339-52. 10.1172/JCI93521

30. Łęgosz P, Drela K, Pulik Ł, Sarzyńska S, Małdyk P: Challenges of heterotopic ossification-Molecular background and current treatment strategies. Clin Exp Pharmacol Physiol. 2018, 45:1229-35. 10.1111/14401681.13025

31. Zakrasek EC, Yurkiewicz SM, Dirlikov B, Pence BT, Crew JD: Use of nonsteroidal anti-inflammatory drugs to prevent heterotopic ossification after spinal cord injury: a retrospective chart review. Spinal Cord. 2019, 57:214-20. 10.1038/s41393-018-0199-3

32. Müseler AC, Grasmücke D, Jansen O, Aach M, Meindl R, Schildhauer TA, Citak M: In-hospital outcomes following single-dose radiation therapy in the treatment of heterotopic ossification of the hip following spinal cord injury-an analysis of 444 cases. Spinal Cord. 2017, 55:244-6. 10.1038/sc.2016.112

33. Cipriano C, Pill SG, Rosenstock J, Keenan MA: Radiation therapy for preventing recurrence of neurogenic heterotopic ossification. Orthopedics. 2009, 32:10.3928/01477447-20090728-33

34. Banovac K: The effect of etidronate on late development of heterotopic ossification after spinal cord injury . J Spinal Cord Med. 2000, 23:40-4. 10.1080/10790268.2000.11753507

35. Hannallah D, Peng H, Young B, Usas A, Gearhart B, Huard J: Retroviral delivery of Noggin inhibits the formation of heterotopic ossification induced by BMP-4, demineralized bone matrix, and trauma in an animal model. J Bone Joint Surg Am. 2004, 86:80-91. 10.2106/00004623-200401000-00013

36. Glaser DL, Economides AN, Wang L, et al.: In vivo somatic cell gene transfer of an engineered Noggin mutein prevents BMP4-induced heterotopic ossification. J Bone Joint Surg Am. 2003, 85:2332-42. 10.2106/00004623-200312000-00010

37. Peterson JR, De La Rosa S, Eboda O, et al.: Treatment of heterotopic ossification through remote ATP hydrolysis. Sci Transl Med. 2014, 6:255ra132. 10.1126/scitranslmed.3008810

38. Yu PB, Deng DY, Lai CS, et al.: BMP type I receptor inhibition reduces heterotopic [corrected] ossification . Nat Med. 2008, 14:1363-9. 10.1038/nm.1888

39. Strong AL, Spreadborough PJ, Dey D, et al.: BMP ligand trap ALK3-Fc attenuates osteogenesis and heterotopic ossification in blast-related lower extremity trauma. Stem Cells Dev. 2021, 30:91-105. $10.1089 / \mathrm{scd} .2020 .0162$

40. Chakkalakal SA, Uchibe K, Convente MR, et al.: Palovarotene inhibits heterotopic ossification and maintains limb mobility and growth in mice with the human ACVR1(R206H) fibrodysplasia ossificans progressiva (FOP) mutation. J Bone Miner Res. 2016, 31:1666-75. 10.1002/jbmr.2820

41. Shimono K, Tung WE, Macolino C, et al.: Potent inhibition of heterotopic ossification by nuclear retinoic acid receptor- $\gamma$ agonists. Nat Med. 2011, 17:454-60. 10.1038/nm.2334

42. Wheatley BM, Cilwa KE, Dey D, et al.: Palovarotene inhibits connective tissue progenitor cell proliferation in a rat model of combat-related heterotopic ossification. J Orthop Res. 2018, 36:1135-44. 10.1002/jor.23747

43. An Efficacy and Safety Study of Palovarotene for the Treatment of Fibrodysplasia Ossificans Progressiva . (2017). https://clinicaltrials.gov/ct2/show/NCT03312634.

44. Arriola Apelo SI, Lamming DW: Rapamycin: an InhibiTOR of aging emerges from the soil of Easter Island . J Gerontol A Biol Sci Med Sci. 2016, 71:841-9. 10.1093/gerona/glw090

45. Qureshi AT, Crump EK, Pavey GJ, Hope DN, Forsberg JA, Davis TA: Early Characterization of Blast-related Heterotopic Ossification in a Rat Model. Clin Orthop Relat Res. 2015, 473:2831-9. 10.1007/s11999-0154240-y

46. Maekawa H, Kawai S, Nishio M, et al.: Prophylactic treatment of rapamycin ameliorates naturally developing and episode -induced heterotopic ossification in mice expressing human mutant ACVR1. Orphanet J Rare Dis. 2020, 15:122. 10.1186/s13023-020-01406-8

47. Zimmermann SM, Schwitter LW, Scheyerer MJ, et al.: Prevention of heterotopic ossification: an experimental study using a plasma expander in a murine model. BMC Surg. 20164, 16:29. 10.1186/s12893016-0144-3

48. Vanden Bossche LC, Van Maele G, Wojtowicz I, et al.: Free radical scavengers versus methylprednisolone in the prevention of experimentally induced heterotopic ossification. J Orthop Res. 2009, 27:748-51. 10.1002/jor.20817

49. Kaplan FS, Andolina JR, Adamson PC, et al.: Early clinical observations on the use of imatinib mesylate in FOP: a report of seven cases. Bone. 2018, 109:276-80. 10.1016/j.bone.2017.07.019

50. Werner CM, Zimmermann SM, Würgler-Hauri CC, Lane JM, Wanner GA, Simmen HP: Use of imatinib in the prevention of heterotopic ossification. HSS J. 2013, 9:166-70. 10.1007/s11420-013-9335-y 